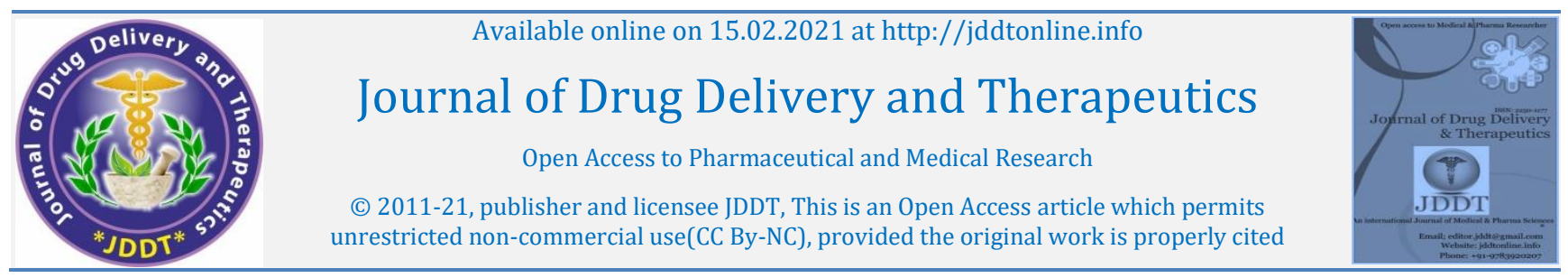

(C) 2011-21, publisher and licensee JDDT, This is an Open Access article which permits Open Access Full Text Article

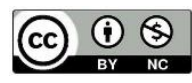

Research Article

\title{
An Introspection on the need of medication compliance in geriatric patients with hypertension
}

\author{
S Nivya, *Nimmy N John, Aksa Maria Thomas \\ Department of Pharmacy Practice, N.E.T Pharmacy College, Raichur, Karnataka-584103, India
}

\section{Article Info:}

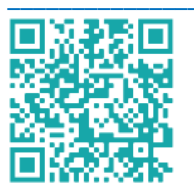

\section{Article History:}

Received 07 Dec 2020;

Review Completed 28 Jan 2021

Accepted 06 Feb 2021:

Available online $15 \mathrm{Feb} 2021$

\section{Cite this article as:}

Nivya S, John NJ, Thomas AM, An Introspection on the need of medication compliance in geriatric patients with hypertension, Journal of Drug Delivery and Therapeutics. 2021; 11(1-s):57-61 DOI: http://dx.doi.org/10.22270/jddt.v11i1-s.4747

\section{Address for Correspondence:}

Mrs. Nimmy N John, Assistant Professor, Department of Pharmacy Practice, NET Pharmacy College, Raichur- 584103 Karnataka, India

\section{Abstract}

Introduction: Medication compliance is consequential part of treatment success. Medication non- compliance in geriatric patients leads to substantial worsening of disease, increased healthcare costs, and death. Financial constraints and adverse events or side effects associated with non-compliance can be avoided by improving medication compliance. Objective: To assess the level of medication compliance in geriatric patients and to analyse factors causing non-compliance to medications. Methods: This cross-sectional study was carried out from May 2020 to July 2020 in a rural area of South India. 150 geriatric patients (aged $>60$ years) attending the Non- Communicable Disease (NCD) clinics in Primary Health Centres (PHC) were interviewed using validated questionnaires. Results: A total of 150 geriatric participants with Hypertension were assessed for the level of compliance for long term medications. Maximum numbers of participants were males (54\%) and majority were found in the age group of $61-70(42 \%)$ and good compliance was observed in $63 \%$ of the participants and suggests that the compliance level has decreased progressively with increasing age. Good compliance was seen in subjects with up to 2 medications (55\%) compared to more than 2 medications (25\%). The level of compliance was good in $47 \%$, moderate in $35 \%$ and poor in $18 \%$ of the participants. Conclusion: This study shows poor compliance to the prescribed medication among geriatric subjects with chronic diseases. Different strategies should be used to increase medication compliance in geriatric patients to achieve better outcomes in their health status.

Keywords: Medication compliance, Hypertension, geriatric patients

\section{INTRODUCTION}

Geriatric care management plans and coordinates care of the elderly with physical or mental impairments to meet their long term care needs, improve their quality of life, and maintain their independence. According to World Population Prospects 2019, by 2050, 1 in 6 people in the world will be over the age of 65 . Globally, the population aged above 60 years is increasing due to better life expectancy and thereby this led to some of the health problems among them being proportionally increased. As older adults often suffer from multiple comorbid conditions and thus use more medication, medication noncompliance can have drastic health effects on the geriatric patients, including polypharmacy, adverse effects, cost, inability to get a prescription. The care of the aged is gradually showing shift from family to community level as old age home concept extensively. ${ }^{1}$

There are many rationales to non- compliance of patients to their prescribed medication regimens. These reason ns to barriers describe patient, prescriber and health care system factors which reason out the fact that medication use process is affected by many factors in older adults, including drugand patient-related factors such as patient understandings about their illness, cognitive function, and medication side effects, as well as other factors. Therefore, finding potential areas for interventions among healthcare providers is important. ${ }^{2}$. Helpless consistence among more established people represents unfavourable results, drug wastage with expanded expense of medical care, and significant deteriorating of the illness with expanded handicap or passing. Be that as it may, not many examinations have been done in Indian populance to survey the issue and the degree of prescription consistence in geriatric patients and to investigate the different components contributing the human and financial expenses related with noncompliance. ${ }^{3}$

Drug consistence is the demonstration of taking prescription on time or accepting medicine as endorsed, which un announces that the patient has a decision and that both patient and suppliers commonly set up the therapy objectives and the clinical routine. Information about the impacts and motivation behind prescription decidedly connected with drug consistence. Understanding advising assumes a significant part in forestalling drug rebelliousness and in making home consideration more viable. Henceforth, it is significant for a drug specialist to help out other consideration laborers, including the consideration administrator to give composed data of professionally prescribed medication to parental figures and home laborers just as to old patients. Tolerant prescription consistence ought to be kept up as an essential piece of geriatric patient consideration with different sicknesses. Medicine consistence ought to be covered by performing drug history and prescription subtleties of patients. ${ }^{4}$ 


\section{MATERIALS AND METHODS:}

\section{Study design and Subjects}

A cross sectional study was conducted for a period of three months from May 2020 to July 2020 in the rural areas of Thiruvananthapuram district, Kerala. The study used a prospective audit of 150 geriatric patients with Hypertension living in the rural areas of Thiruvananthapuram district aged above 60 years attending Non- Communicable Disease Clinics (NCDs). Geriatric patients, who were unable to hear, speak and severely ill, illiterates and those who are not willing to participate are excluded from the study.

\section{Ethical clearance:}

The ethical approval to conduct the study was obtained from the Ethical Review Committee. Written consents were obtained from each participant.

\section{Participant recruitment and study method}

Permission was obtained from the ethical clearance committee before beginning of study. 150 geriatric patients with Hypertension attending NCD clinics are included in the study after obtaining their prior consent. The data was collected by interviewing all the eligible subjects willing to participate in the study. An 8- item MMAS questionnaire, 11 item pre- validated BMQ Questionnaire and 14 item HillBone Questionnaire was used for assessing the medication adherence in the patient.

Patients were asked regarding registration in client and clinic registration, minimum 4 NCD check-up visits in a month, taking anti- hypertensive tablets, improving their lifestyle modifications including like DASH diet and exercises. They were also asked about the symptoms, if shown. The high blood pressure can result in nosebleeds, headaches, or dizziness.

\section{RESULTS AND DISCUSSION:}

\section{RESULT:}

The socio-demographic data of the participant are given in Table 1.Table 2 shows that the level of compliance in geriatric patients. The different types of prescribed medication or on-going therapy are given in the Table 3 . Table 4 shows that the factors affecting the medication compliance in geriatric patient. Table 5 shows different reasons for missing medications. Figure 1 shows the factors affecting the medication compliance in geriatric patients. Figure 2 shows the reasons for missing the medication

In this study, a total of 150 geriatric participants with Hypertension were assessed for the level of compliance for long term medications. Maximum number of participants was males (54\%) and majority were found in the age group of $61-70(42 \%)$ and good compliance was observed in $63 \%$ of the participants and suggests that the compliance level has decreased progressively with increasing age. Good compliance was seen in subjects with up to 2 medications (55\%) compared to more than 2 medications $(25 \%)$. The level of compliance was good in $47 \%$, moderate in $35 \%$ and poor in $18 \%$ of the participants.

Table 1: Socio demographics of geriatric patients

\begin{tabular}{|c|c|c|}
\hline Variables & $\begin{array}{l}\text { Frequency } \\
(N=150)\end{array}$ & $\begin{array}{l}\text { Percentage } \\
\text { (\%) }\end{array}$ \\
\hline Age & \multirow[b]{2}{*}{63} & \multirow[b]{2}{*}{42} \\
\hline $61-70$ & & \\
\hline $71-80$ & 51 & 34 \\
\hline $81-90$ & 30 & 20 \\
\hline$>90$ & 6 & 4 \\
\hline Gender & \multirow{3}{*}{$\begin{array}{l}81 \\
69\end{array}$} & \multirow{3}{*}{$\begin{array}{l}54 \\
46\end{array}$} \\
\hline Male & & \\
\hline Female & & \\
\hline Education & \multirow{5}{*}{$\begin{array}{l}81 \\
49 \\
12 \\
8\end{array}$} & \multirow{5}{*}{$\begin{array}{l}54 \\
33 \\
8 \\
5\end{array}$} \\
\hline Primary & & \\
\hline Secondary & & \\
\hline Degree / diploma & & \\
\hline Post-graduation & & \\
\hline Occupation & \multirow{4}{*}{$\begin{array}{l}86 \\
21 \\
43\end{array}$} & \multirow{4}{*}{$\begin{array}{l}57 \\
14 \\
29\end{array}$} \\
\hline Unemployed & & \\
\hline Business & & \\
\hline Others & & \\
\hline
\end{tabular}

Table 2: Level of compliance

\begin{tabular}{|c|c|}
\hline Level of Compliance* $^{*}$ & N=150 (\%) \\
\hline Good & $71(47)$ \\
\hline Moderate & $52(35)$ \\
\hline Poor & $27(18)$ \\
\hline
\end{tabular}

Table 3: Prescribed medication/ ongoing therapy

\begin{tabular}{|c|c|c|c|}
\hline \multicolumn{2}{|c|}{ Anti- Hypertensives } & Number of subjects & Percentage \\
\hline 1 & Calcium channel blockers & 56 & 4 \\
\hline 2 & ACE inhibitors & 6 & 23 \\
\hline 3 & Angiotensin Receptor Blockers & 10 & 7 \\
\hline 4 & Beta- blockers & 3 & 2 \\
\hline 5 & Alpha- blockers & 41 & 27 \\
\hline 6 & Combinations & & 4 \\
\hline
\end{tabular}


Table 4: Factors affecting medication compliance

\begin{tabular}{|c|c|c|c|c|}
\hline \multicolumn{2}{|c|}{ Factors } & \multicolumn{3}{|c|}{ Compliance } \\
\hline & & \multirow{2}{*}{$\begin{array}{l}\text { Poor } \\
9(14 \%)\end{array}$} & \multirow{2}{*}{$\begin{array}{l}\text { Moderate } \\
14(22 \%)\end{array}$} & \multirow{2}{*}{$\begin{array}{l}\text { Good } \\
40(63 \%)\end{array}$} \\
\hline Age & $61-70$ & & & \\
\hline & $71-80$ & $7(14 \%)$ & $33(65 \%)$ & $11(22 \%)$ \\
\hline & $81-90$ & $2(7 \%)$ & $19(63 \%)$ & $9(30 \%)$ \\
\hline & $>90$ & $4(67 \%)$ & $2(33 \%)$ & 0 \\
\hline \multirow[t]{2}{*}{ Gender } & Male & $8(10 \%)$ & $12(15 \%)$ & $61(75 \%)$ \\
\hline & Female & $5(7 \%)$ & $10(14 \%)$ & $54(78 \% 0$ \\
\hline \multirow[t]{4}{*}{ Educational status } & Primary & $11(14 \%)$ & $29(36 \%)$ & $41(51 \%)$ \\
\hline & Secondary & $8(16 \%)$ & $18(37 \%)$ & $23(47 \%)$ \\
\hline & Degree & $2(17 \%)$ & $3(25 \%)$ & $7(58 \%)$ \\
\hline & PG & 0 & $1(13 \%)$ & $7(88 \%)$ \\
\hline \multirow[t]{2}{*}{ Family income } & $1000-10000$ & $6(6 \%)$ & $24(26 \%)$ & $64(68 \%)$ \\
\hline & $>10000$ & $2(4 \%)$ & $20(36 \%)$ & $34(61 \%)$ \\
\hline \multirow[t]{3}{*}{ Family status } & Living alone & $2(14 \%)$ & $4(29 \%)$ & $8(57 \%)$ \\
\hline & With spouse & $6(13 \%)$ & $12(25 \%)$ & $30(63 \%)$ \\
\hline & With family & $8(9 \%)$ & $24(27 \%)$ & $56(64 \%)$ \\
\hline \multirow[t]{2}{*}{ No: of medications } & Up to 2 & $11(11 \%)$ & $33(34 \%)$ & $53(55 \%)$ \\
\hline & $>2$ & $14(26 \%)$ & $26(49 \%)$ & $13(25 \%)$ \\
\hline \multirow[t]{2}{*}{ Awareness about disease } & Yes & $2(2 \%)$ & $28(28 \%)$ & $70(70 \%)$ \\
\hline & No & $4(8 \%)$ & $7(14 \%)$ & $39(78 \%)$ \\
\hline \multirow[t]{2}{*}{ Side effects } & Yes & $5(5 \%)$ & $31(28 \%)$ & $74(67 \%)$ \\
\hline & No & 0 & $11(28 \%)$ & $29(73 \%)$ \\
\hline
\end{tabular}

Table 5: Reasons for missing medications

\begin{tabular}{|c|c|c|}
\hline Sl. No & Reasons & No: of subjects \\
\hline 1 & Forgetfulness & 8 \\
\hline 2 & Poly pharmacy & 5 \\
\hline 3 & Complexity of regimen & 2 \\
\hline 4 & Lack of time & 1 \\
\hline 5 & Side effects or adverse events & 2 \\
\hline 6 & Dependency on care taker & 7 \\
\hline 7 & Financial constraints & 2 \\
\hline
\end{tabular}




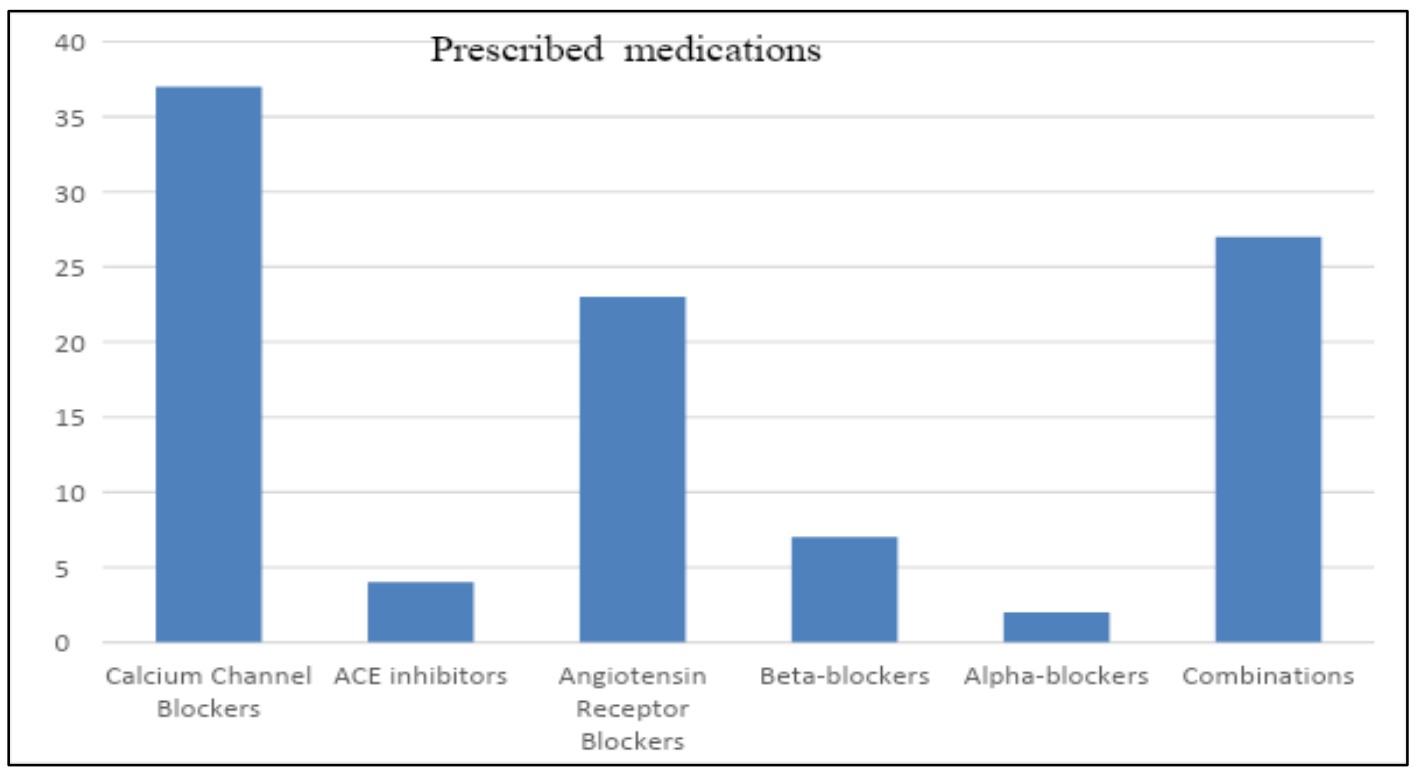

Figure 1: Prescribed medication/ ongoing therapy

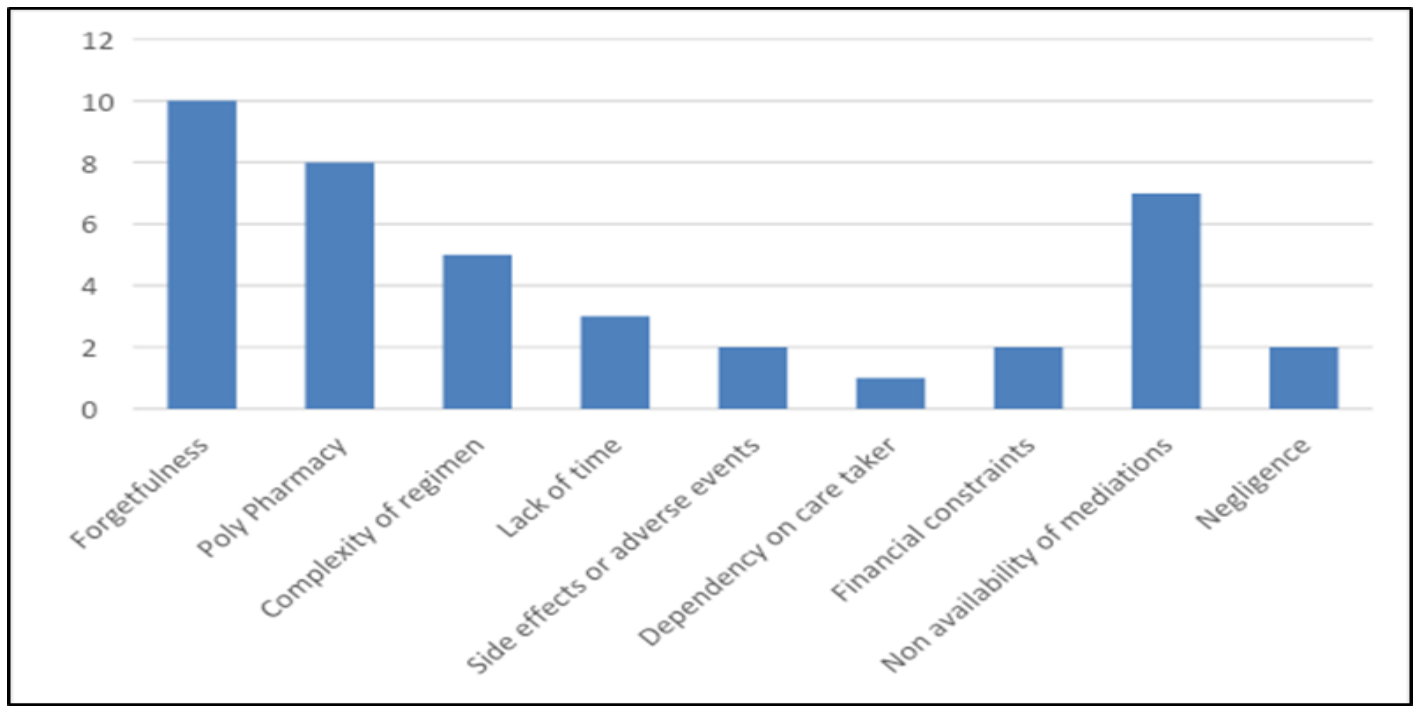

Figure 2: Reasons for missing medications.

\section{DISCUSSION:}

Non-Communicable Disease (NCD) clinics have a potentially critical role in the improvement of geriatric health. The NCD provides an estimate of essential health issues, including health promotion, disease prevention, screening, and diagnosis. The health services avail oneself of to conserve the physical and mental well-being of the elderly patients, to prevent complications of Hypertension, to improve lifestyle by including exercises and DASH diet. A cross sectional study was carried out by assessing the level of medication compliance in 150 geriatric patients with Hypertension to analyse the factors influencing medication compliance and to improve health practices in geriatric populations

Among the total participants, age was taken into consideration by dividing into 4 age groups being kept an interval of 10 years each. Maximum number of participants was found in the age group of 61-70 (42\%) followed by 71 $80(34 \%)$ and $81-90(20 \%)$ and least were found in age group of $>90(4 \%)$. The age group characteristics were similar to the study conducted by Reshmi P S et al ${ }^{5}$. The data suggests that the youngest old age group of geriatric population (61-70) visits NCD clinics more than others.
According to my study, a majority of the participants were males (54\%) and $46 \%$ were females, similar to the finding of Reshmi P S et al that the male participants outnumbered female participants.

Geriatric patients enrolled in the study had a mixed educational background. Majority of the participants 81 (54\%) were having primary education. Some participants were having secondary/senior secondary 49 (33\%), degree $12(8 \%)$ and post-graduation $8(5 \%)$ educational levels. This shows that increase in medication non-compliance is due to low educational status and presumed that the education may play a definite role in improving medication compliance by making the participants understand better regarding the nature of their disease, the importance of treatment, physician's instructions and advice. Majority of the participants in the study were unemployed 86(57\%) followed by others 43 (29\%) and business 21 (14\%) which signifies that they were poorly socio-economic. The same is shown in Table 1.

The validity and reliability reported with the 8-item questionnaire and its use in the geriatric patients to identify non-compliance and the risk for uncontrolled blood 
pressure. This sensitivity of $71(47 \%)$ indicates that the scale is good at identifying patients who have low medication compliance and have uncontrolled blood pressure. The specificity of the eight-item scale of 52 (35\%) indicates moderate compliance of the scale, followed by poor compliance in $27(18 \%)$. These findings were similar to the study done by Morisky D E et al ${ }^{6}$ in Table 2.

Among 150 geriatric participants, maximum number of respondents 56 (37\%) were administered with Calcium channel blockers and 41 (27\%) respondents were administered with combination of anti- hypertensive drugs. About 34 (23\%) participants administered with Angiotensin Receptor Blockers and $10(7 \%)$ participants given beta blockers. Almost 6 (4\%) with Angiotensin Converting Enzyme inhibitors and Alpha blockers is administered in 3 (2\%) participants. Participants with good ability to recall medications showed a high level of compliance. The awareness among the study participants about their illnesses and prescribed medications showed an association with the level of compliance as similar to study conducted by Sruthi $\mathbf{R}$ et al. ${ }^{3}$ and it is presented in Table $\mathbf{3}$ and Figure $\mathbf{1}$.

Good compliance was observed in $63 \%$ of the participants in the age group of $61-70$ years, $22 \%$ in the age between $71-80$ years and $30 \%$ in participants with $81-90$ and none of the participants above 91 years. The level of compliance was poor in $14 \%$ of the participants of $61-70$ years age group and $67 \%$ in the age above 91 years. These observations suggest that the compliance level has decreased progressively with increasing age, which may affect the medication compliance, probably because of the age-related functional decline.

There was a constructive link between educational status and compliance level. Hence it can be spectacles that the education may play a definite role in improving medication compliance by making the participants to understand better regarding the nature of their disease, the importance of treatment, physician's instructions and advice. Another reason which may determine the modest for the healthcare services and medication compliance is the financial status of the participants or their family. However, in the present study the family income had moderately influenced the medication compliance in the participants. The compliance level was much higher in those subjects living with spouse or with family compared to those living alone.

Good compliance was seen in subjects with up to 2 medications (55\%) compared to more than 2 medications $(25 \%)$. The number of medications has a direct relation with medication compliance as the participants with multiple illnesses require a higher number of medications with complex dosing regimen and increased medication costs, while the other side needs simpler dosing regimen requiring a smaller number of medications. The awareness among the participants about their illnesses and prescribed medications showed an interconnection with the level of compliance. The subjects who were regular for the follow-up visits generally showed better medication compliance and also the compliance was better in those who did not experience any side effects or adverse events.

In general, the low level of compliance was generally related to advancing age, lack of family and social support, multiple medications with complex regimen, lack of proper awareness about their illnesses and medications and occurrence of adverse effects. The study conducted by Jin $\mathbf{H}$ et al ${ }^{7}$ showed the similar results in Table 4.
The misplacement of the medications was mainly due to polypharmacy, complexity of regimen, forgetfulness, financial constraints and non -availability of the medications. Since the finest therapeutic outcome involves a good patient compliance to the prescribed medications, which can be improved by reducing the number of medications, simplifying the regimen, less frequent dosing, use of long acting formulations, cost-effective medications, avoiding the inconvenient side effects/adverse events, proper inducement of the patients and their caregivers for regular follow-up and also by effective patient education and counselling to create a proper awareness about their disease states and medications. The same is represented in Table $\mathbf{5}$ and Figure $\mathbf{2}$ conducted by Park H Yet al. 8

\section{CONCLUSION:}

This study shows a modest compliance to the prescribed medication among geriatric participants with Hypertension. It is observed that the quality of health care services to the geriatric population in this area must be improved to reduce the burden of diseases and disabilities by education and awareness of the family members as well as health workers. Drug factors such as less expensive, health insurance, and less in number are associated with better compliance. Different schemes should be used to increase medication compliance in geriatric patients to achieve better outcomes in their health status.

\section{Conflict of Interest:}

Authors report no conflict of interest in publishing this research work.

\section{ACKNOWLEDGEMENT:}

The authors thank the geriatric patients who participated in this study, for their time and willingness to share their experiences and perceptions. They also thank the local people and health centres of the study area.

\section{REFERENCES:}

1. Jaiganesh D, Prasad KN, Janaki M. Cross Sectional Study on Health Problems among Elderly inmates of Old age Homes in Urban areas of Chennai, India, International Journal of Recent Trends in Science and Technology, ISSN 2277-2812 E-ISSN 2249-8109, 2013; 9(1).

2. Walid F. Gellad, MD, MPH1, 2,3, Jerry L. Grenard. A Systematic Review of Barriers to Medication Adherence in the Elderly: Looking Beyond Cost and Regimen Complexity, Am J Geriatr Pharmacother. 2011; 9(1):11-23. doi: 10.1016/j.amjopharm.2011.02.004.

3. Shruthi R, Jyothi R. A Study of Medication Compliance in Geriatric Patients with Chronic Illnesses at a Tertiary Care Hospital, J Clin Diagn Res. 2016; 10(12):FC40-FC43.

4. Salamaa AA, Yasin AEA. Medication knowledge as a determinant of medication adherence in geriatric patients, Serse Elian City, Menoufia Governorate, Egypt, Menoufia Medical Journal, 2017; $30(11)$.

5. Reshmi PS. A cross sectional study on the health status of geraitric population, Int J Community Med Public Health. 2016; 3(6):1477-1480

6. Morisky DE, ScD, MSPH, Alfonso Ang, PhD, Marie Krousel-Wood, MD, MSPH, and Harry J. Ward, MD. Predictive Validity of A Medication Adherence Measure in an Outpatient Setting. J Clin Hypertens (Greenwich). 2008; 10(5):348-354.

7. Jin H, Kim Y. Factors affecting medication adherence in elderly people, Patient Prefer Adherence. 2016; 10:2117-2125

8. Hwa Yeon Park, Sin Ae Seo, Hyeyoung Yoo, Kiheon Lee. Medication adherence and beliefs about medication in elderly patients living alone with chronic diseases, Patient Prefer Adherence. 2018; 12:175-181. 